\title{
The optical coherence tomography angiography manifestation of strabismus amblyopia with eccentric fixation
}

\section{Hongxing Ren}

Wuhan Aier Eye Hospital https://orcid.org/0000-0001-5736-7303

Jing Cheng

Wuhan Aier Eye Hospital

Aijiao Qin

Wuhan Aier Eye Hospital(hanyang)

Minghua Shi (D13995559689@163.com )

Wuhan Aier Eye Hospital https://orcid.org/0000-0002-5715-7012

Research article

Keywords: strabismus, amblyopia, eccentric fixation

Posted Date: June 18th, 2020

DOl: https://doi.org/10.21203/rs.3.rs-34865/v1

License: (c) (i) This work is licensed under a Creative Commons Attribution 4.0 International License.

Read Full License 


\section{Abstract}

\section{Background}

To explore the application value of optical coherence tomography angiography (OCTA) in patients with strabismus amblyopia accompanied by eccentric fixation.

\section{Methods}

The following data were collected from patients with strabismus amblyopia accompanied by eccentric fixation: best corrected visual acuity (BCVA); spherical equivalent (SE) and deviation angle; eccentric fixation distance using OCTA system software tools, with $\mu \mathrm{m}$ as the unit of measurement of the distance between the retinal fixed point and the macular fovea; macular fovea vessel length density (VLD); perfusion density (PD); foveal avascular zone (FAZ) area; and perimeter and circularity of the superficial retinal vascular plexus. The entry criteria were as follows: OCTA scanning quality and signal strength of 8 or above (range 0 to 10 ).

Results

Data from a total of 34 patients were collected: 17 patients with strabismus amblyopia with eccentric fixation were included in the experimental group, and 17 patients without strabismus with central fixation were included in the control group. The average deviation angle of the experimental group was $26.71 \pm$ 25.88 prism dioptres (PD), the amblyopic eye BCVA was $0.24 \pm 0.22$, the SE was $4.35 \pm 2.98 \mathrm{D}$, the stereoscopic median was 800", the eccentric fixation distance was $632.18 \pm 310.62 \mu \mathrm{m}$, the macular fovea retinal thickness was $207.82 \pm 17.79 \mu \mathrm{m}$, the VLD of the superficial retinal vascular plexus was $7.31 \pm 3.84 \mathrm{~mm}^{-1}$, the PD was $0.16 \pm 0.08$, the FAZ area was $0.28 \pm 0.17 \mathrm{~mm}^{2}$, the FAZ perimeter was $2.05 \pm 0.56 \mathrm{~mm}$, and the FAZ circularity was $0.67 \pm 0.06$. These results showed statistically significant differences in the SE and BCVA compared with the lateral eye and the control group, but there were no statistically significant differences in the macular fovea retinal thickness, VLD, PD, or FAZ. The eccentric fixation of amblyopic eyes was directly related to the deviation angle, and the regression formula was as follows: the eccentric fixation distance of amblyopic eyes $=8.319 \times$ the deviation angle $+410.002(\mathrm{~F}=$ 13.878, $P=0.002<0.01)$.

\section{Conclusion}

The eccentric fixation distance of strabismus amblyopia with eccentric fixation is related to the deviation angle; the greater the deviation angle is, the greater the distance of eccentric fixation.

Trial registration

Chinese Clinical Trial Registry, ChiCTR1900022830. Registered 27 April 2019, http://www.chictr.org.cn/

\section{Background}


Strabismus amblyopia can be accompanied by eccentric fixation; if the eccentric fixation does not change to central fixation, amblyopia is very difficult to treat [1-3]. Eccentric fixation has always been observed via direct ophthalmoscopy, but the description of the results is relatively subjective. In our clinical practice, we found that in patients with central fixation, the central fovea of the macula was coincident with the central point of the image in OCTA, while in patients with eccentric fixation, the central fovea of the macula was separated from the central point of the image. Therefore, we regard the central point of the image as a fixation point, hoping that through OCTA, we can record the eccentric distance by measuring the distance between the central point of the image and the central fovea of the macula. The patients have better compliance, and the results can be quantified and are relatively objective. The aim of this study is to observe whether there are differences between patients with strabismus amblyopia with eccentric fixation and patients without strabismus as well as to further understand the pathogenesis and clinical characteristics of this kind of disease in order to provide treatment guidance.

\section{Methods}

\section{Subjects}

From May 2019 to May 2020, patients with strabismus amblyopia with eccentric fixation in our hospital were included: 17 patients in the experimental group and 17 patients in the control group. All patients underwent eye examinations that included the following data: SE, BCVA, eye movement, in parallel with slit lamp and ophthalmoscopy, prism, and stereopsis. The exclusion criteria were as follows: refractive stromal opacity, fundus disease and nystagmus. This study was approved by the ethics committee of

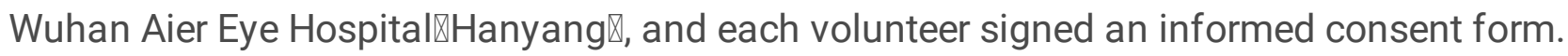

\section{Instruments and recording methods}

Recording method: Cirrus HD-OCT 5000 (version 9.5.2.19038, Zeiss, Germany) was used for macular cube $512 \times 128$ and angiograph $3 \mathrm{~mm} \times 3 \mathrm{~mm}$ scanning. Before image acquisition, the refractive error was adjusted (adjustment range was $-20.00 \sim+20.00 \mathrm{D}$ ), and the patient was instructed to gaze at the centre of the green fixation object. The FastTrac ${ }^{\mathrm{TM}}$ tracking function was turned on to observe the patient's fixation in real time. All patients had scan quality signals of 8 or above before the results were recorded. We took the central point of the scanning range as the fixation point and used the measurement tool of OCT system software to measure the distance between the fixation point and the macular fovea. The unit was $\mu \mathrm{m}$ (fig. 1). The scan was repeated a few times until the measured distance results were not different. The examination data were imported into the FORUM system, and Angio-plex ${ }^{\mathrm{TM}}$ software was used for automatic blood flow quantitative analysis (fig 2). The OCTA examination of all subjects was completed independently by the same skilled ophthalmologist, and all results were checked and examined by another resident physician.

\section{Data analysis}


Data analysis was performed using IBM SPSS Statistics software 20. All the data for the normality test, in accordance with normal distribution data, were compared between experimental amblyopia eyes and lateral eyes with paired $t$ tests. The data of the experimental group was compared with that of the control group using independent sample t tests. For data that did not conform to a normal distribution, the comparison between experimental amblyopia eyes and lateral eyes was performed using the Wilcoxon test. Data from the experimental group was compared with that from the control group using the MannWhitney $U$ test, and simple linear regression was used to obtain the influencing factors of the eccentric fixation distance. Spearman rank correlation analysis was adopted for the correlation between the degree of amblyopia and each factor, and $\mathrm{P} \bigotimes 0.05$ was considered statistically significant.

\section{Results}

\section{Baseline information:}

The experimental group included patients aged $13.88 \pm 9.73$ years: 8 male patients aged $15.50 \pm 12.80$ years and 9 female patients aged $12.44 \pm 6.43$ years. The amblyopic eye BCVA was $0.24 \pm 0.22$, and the proportions of light, medium and severe amblyopia were $24 \%, 35 \%$, and $41 \%$. The amblyopic eye SE was $4.35 \pm 2.98 \mathrm{D}$, the median Titmus stereopsis was $800 "$ ", the lateral eye median BCVA was 1.0 , and the lateral eye SE was $2.64 \pm 2.29 \mathrm{D}$; except for 4 cases of myopia, the remaining patients had hyperopic eyes (table 1). The patients in the control group were 16.29 \pm 12.92 years old: there were 7 males with an average age of $13.86 \pm 12.52$ years and 10 females with an average age of $18.00 \pm 13.57$ years. The median BCVA was 1.0, the SE was $2.06 \pm 1.49 \mathrm{D}$, and the Titmus stereopsis was $108.24 \pm 33.21$ " (tables $1,2)$.

\section{Main results}

In the experimental group, the deviation angle was $26.71 \pm 25.88$ PD; the amblyopic eye eccentric fixation distance was $632.18 \pm 310.62 \mu \mathrm{m}$, except for 2 cases of bilateral eccentric fixation; the amblyopic eye macular fovea retinal thickness was $207.82 \pm 17.79 \mu \mathrm{m}$; and the lateral eye macular fovea retinal thickness was $207.06 \pm 18.63 \mu \mathrm{m}$. In the control group, the macular fovea retinal thickness was 209.47 $\pm 13.89 \mu \mathrm{m}$, which was not significantly different compared with the experimental amblyopia eyes $(P=$ 0.883 and $P=0.765)$. In the amblyopia eyes, the superficial retinal vascular plexus macular fovea VLD was $7.31 \pm 3.84 \mathrm{~mm}^{-1}$, the PD was $0.16 \pm 0.08$, the FAZ area was $0.28 \pm 0.17 \mathrm{~mm}^{2}$, the FAZ perimeter was $2.05 \pm 0.56 \mathrm{~mm}$, and the FAZ circularity was $0.67 \pm 0.06$. In the lateral eyes, the macular fovea VLD was $7.29 \pm 2.50 \mathrm{~mm}^{-1}$, the PD was $0.17 \pm 0.07$, the FAZ area was $0.31 \pm 0.13 \mathrm{~mm}^{2}$, the FAZ perimeter was $2.26 \pm 0.54 \mathrm{~mm}$, and the FAZ circularity was $0.69 \pm 0.10$. In the control group, the macular fovea VLD was $7.89 \pm 3.87 \mathrm{~mm}^{-1}$, the PD was $0.17 \pm 0.10$, the FAZ area was $0.31 \pm 0.13 \mathrm{~mm}^{2}$, the FAZ perimeter was $2.17 \pm 0.45 \mathrm{~mm}$, and the FAZ circularity was $0.69 \pm 0.10$ (tables 1,2 ).

Through scatter plot analysis, it was found that there was a linear correlation between squint and the eccentric fixation distance, so the linear regression analysis was carried out between the eccentric fixation 
distance and the deviation angle, and the regression equation was obtained: the eccentric fixation distance $=8.319 \times$ the deviation angle $+410.002(F=13.878, P=0.002<0.01)(F I G .3)$. The degree of amblyopia was positively correlated with the deviation angle by Spearman correlation analysis $(r=0.574$, $P=0.016<0.05)$.

\section{Discussion}

OCTA is a relatively new non-invasive imaging technique that uses dynamic and static tissue contrast imaging to obtain high-resolution information and generate blood flow to angiographic images. OCTA not only can quantify blood flow VLD, PD, and FAZ areas and more parameters [4-6] but also can be used to quantify the eccentric distance based on OCT technology [7-10], and fixation conditions can be observed by the FastTrac tracking function. In fact, this kind of patient fixation condition is very poor, accounting for $29 \%$. Most patients need a longer time for capturing images with stable fixation, and the size of the eccentric fixation distance has certain fluctuations. We will measure to ensure the accuracy of the results many times, although it conflicts with OCTA inspection requirements, which may have a certain influence on the results of the inspection; however, the side effects reflect the clinical features of this disease, so OCTA research is necessary.

Regarding the cause of eccentric fixation, previous studies have focused on two theories [11]: one is the "correspondence theory", which holds that abnormal retinal correspondence is the cause of eccentric fixation. The other is the " scotoma theory", which holds that eccentric fixation is caused by scotoma in the macular fovea of the strabismus eye. WYBAR believes that eccentric fixation is caused by inhibition of the macular fovea in the strabismus eye, which is a feature of monocular fixation behaviour, while the abnormal retina corresponds to binocular fixation behaviour, and there is no causal relationship between them [12]. Keiner believes that the type of eccentric fixation is related to age; the younger the age that eccentric fixation presents, the more likely it is caused by abnormal vision in the monocular eye, and the older the age that eccentric fixation presents, the more likely it is caused by abnormal retina correspondence [13]. After years of research, Von Noorden found that abnormal retinal correspondence could not explain all the phenomena of eccentric fixation, and eccentric fixation could also occur in the case of normal retinal correspondence [14]. He was more inclined to the theory of scotoma, believing that eccentric fixation was related to the size and degree of inhibition of the scotoma [15]. Wong confirmed that the existence of abnormal retinal tissue is inversely proportional to the deviation angle; the greater the deviation angle is, the smaller the possibility of abnormal retinal correspondence is, and the smaller the deviation angle is, the greater the possibility of abnormal retinal correspondence [16]. In our study, both small-angle strabismus and large-angle strabismus were present, but not all cases of small-angle strabismus had abnormal retinal correspondence. Eccentric fixation is proportional to the deviation angle, and the greater the deviation angle is, the greater the eccentric fixation distance is. At present, eccentric fixation is not associated with abnormal retinal correspondence, and the relationship between central scotoma and eccentric fixation needs further study. 
In our study, the SE of the amblyopic eye was significantly better than that of the lateral eye and the control group eye. The time sequence of strabismus, anisometropia and amblyopia is not always obvious or not found in time. The causal relationship between these three cases is hard to assess. Helveston believes that anisometropia is the cause of small-angle strabismus [17], but Lepard believes that monocular strabismus amblyopia has a strong tendency to retain farsightedness and that anisometropia may be the result, not the cause [18]. Smith analysed non-human primate data of anisometropia, strabismus and amblyopia, concluding that early esotropia can cause hyperopic anisometropia and amblyopia. Early hyperopic anisometropia is an important risk factor for amblyopia, while isolated amblyopia does not result in a significant risk for hyperopia or anisometropia [19]. We prefer the view that anisometropia is a result rather than a cause of strabismus. Helveston found that 20 cases of small strabismus all had a certain degree of stereopsis, with an average of 67 " and a best result of 20" [17]. Epstein studied 15 patients with a stereoscopic average of more than 40". He thought that stereopsis may be associated with the central scotoma size. The smaller the central scotoma was, the better the stereopsis [20]. Our study consisting of small-angle strabismus patients demonstrated rough stereopsis, and patients with large-angle strabismus had almost no stereopsis, with a median of approximately 800 . There was no significant difference compared with the control group, which may be associated with the small sample size. Studies with a small sample size is another important bias factor affecting the outcome.

There are many OCTA studies in fundus diseases; however, in terms of amblyopia, there are fewer studies [21-23]. In addition, in terms of strabismus amblyopia [24], most of the research results show no significant difference between amblyopia eyes and healthy eyes in terms of the capillary plexus vascular density of the macular fovea. Our research conclusions coincide with these research results. As a new examination method, OCTA is expected to be more widely used in the study of strabismus amblyopia in the future.

\section{Conclusion}

We found the eccentric fixation distance of strabismus amblyopia with eccentric fixation is related to the deviation angle; the greater the deviation angle is, the greater the distance of eccentric fixation. There were no statistically significant differences in the macular fovea retinal thickness, VLD, PD, or FAZ.

\section{Declarations}

\section{Acknowledgements}

Not applicable.

\section{Ethics approval and consent to participate}

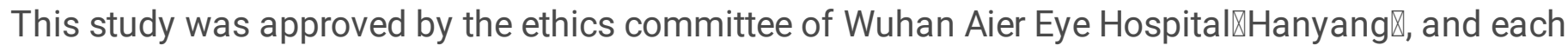
volunteer signed an informed consent form. Written informed consent was obtained from a parent or 
guardian for participants under 16 years old .

\section{Consent for publication}

Not applicable.

\section{Competing interests}

The authors declare that they have no competing interests.

\section{Funding}

The Aier Eye Hospital Group provided research funds. (number : AFQ1708D2 )

\section{Authors' contributions}

Minghua Shi and Hongxing Ren designed study, collected the data . Jing Cheng and Aijiao Qin participated in the collection of data. Hongxing Ren performed statistical analysis, drafted the manuscript and reviewed the literature. Minghua Shi critically reviewed the manuscript. All authors read and approved the final manuscript.

\section{References}

1. Godts D, Mathysen D. Amblyopia with Eccentric Fixation: Is inverse occlusion still an option? J Binocul Vis Ocul Motil. 2019;69(4):131-35.

2. Migliorini R, Comberiati AM, Pacella F, Monsellato R, Arrico L. Anisometropia and isoametropia associated with microstrabismus: effectiveness of late anti-amblyopia treatment. Clin Ter. 2019;170(5):e339-44.

3. Mishra A, Jackson ML. Translational vision rehabilitation: from eccentric fixation to reading rehabilitation. Semin Ophthalmol. 2016;31(1-2):169-77.

4. Lei J, Durbin MK, Shi Y, Uji A, Balasubramanian S, Baghdasaryan E, Al-Sheikh M, Sadda SR. Repeatability and reproducibility of superficial macular retinal vessel density measurements using optical coherence tomography angiography En Face images. JAMA Ophthalmol. 2017;135(10):1092-98.

5. Lim HB, Kang TS, Won YK, Kim JY: The difference in repeatability of automated superficial retinal vessel density according to the measurement area using OCT angiography. J Ophthalmol 2020; 2020:5686894.

6. Carpineto P, Mastropasqua R, Marchini G, Toto L, Di Nicola M, Di Antonio L. Reproducibility and repeatability of foveal avascular zone measurements in healthy subjects by optical coherence tomography angiography. $\mathrm{Br} \mathrm{J}$ Ophthalmol. 2016;100(5):671-76.

7. Nakamoto Y, Takada R, Tanaka M, Matsumoto F, Aomatsu K, Tachibana K, Eguchi H, Kusaka S. Quantification of eccentric fixation using spectral-domain optical coherence tomography. 
Ophthalmic RES. 2018;60(4):231-37.

8. Campbell RJ, Coupland SG, Buhrmann RR, Kertes PJ. Effect of eccentric and inconsistent fixation on retinal optical coherence tomography measures. Arch Ophthalmol. 2007;125(5):624-27.

9. Garcia-Garcia MA, Belda JI, Schargel K, Santos MJ, Ruiz-Colecha J, Rey C, Garcia-Garcia P, Mompean B. Optical coherence tomography in children with microtropia. J Pediatr Ophthalmol Strabismus. 2018;55(3):171-77.

10. Oh IK, Oh J, Kim SW, Huh K. Fixation and photoreceptor integrity in optical coherence tomography. Optom Vis Sci. 2012;89(7):e1000-8.

11. Von Noorden GK, Mackensen G. Phenomenology of eccentric fixation. Am J Ophthalmol. 1962;53:642-60.

12. Wybar K, Thatcher B. Significance of eccentric fixation in squint. Br J Ophthalmol. 1960;44:472-91.

13. Keiner EC. Pathogenesis of eccentric fixation. Am J Ophthalmol. 1967;63(1):20-2.

14. Von Noorden GK. Etiology and pathogenesis of fixation anomalies in strabismus. I. Relationship between eccentric fixation and anomalous retinal correspondence. Am J Ophthalmol. 1970;69(2):210-22.

15. Von Noorden GK. Etiology and pathogenesis of fixation anomalies in strabismus. IV. Roles of suppression scotoma and of motor factors. Am J Ophthalmol. 1970;69(2):236-45.

16. Wong AM, Lueder GT, Burkhalter A, Tychsen L. Anomalous retinal correspondence: neuroanatomic mechanism in strabismic monkeys and clinical findings in strabismic children. J AAPOS. 2000;4(3):168-74.

17. Helveston EM, Von Noorden GK. Microtropia. A newly defined entity. Arch Ophthalmol. $1967 ; 78(3): 272-81$.

18. Lepard CW. Comparative changes in the error of refraction between fixing and amblyopic eyes during growth and development. Am J Ophthalmol. 1975;80(3 Pt 2):485-90.

19. Smith ER, Hung LF, Arumugam B, Wensveen JM, Chino YM, Harwerth RS. Observations on the relationship between anisometropia, amblyopia and strabismus. Vision RES. 2017;134:26-42.

20. Epstein DL, Tredici TJ. Microtropia (monofixation syndrome) in flying personnel. Am J Ophthalmol. 1973;76(5):832-41.

21. Cinar E, Yuce B, Aslan F, Erbakan G. Comparison of retinal vascular structure in eyes with and without amblyopia by optical coherence tomography angiography. J Pediatr Ophthalmol Strabismus. 2020;57(1):48-53.

22. Araki S, Miki A, Goto K, Yamashita T, Yoneda T, Haruishi K, leki Y, Kiryu J, Maehara G, Yaoeda K. Foveal avascular zone and macular vessel density after correction for magnification error in unilateral amblyopia using optical coherence tomography angiography. BMC Ophthalmol. 2019;19(1):171.

23. Yilmaz I, Ocak OB, Yilmaz BS, Inal A, Gokyigit B, Taskapili M. Comparison of quantitative measurement of foveal avascular zone and macular vessel density in eyes of children with 
amblyopia and healthy controls: an optical coherence tomography angiography study. J AAPOS. 2017;21(3):224-28.

24. Pujari A, Chawla R, Mukhija R, Obedulla H, Phuljhele S, Saxena R, Sharma P, Kumar A. Assessment of macular vascular plexus density using optical coherence tomography angiography in cases of strabismic amblyopia. India J Ophthalmol. 2019;67(4):520-21.

\section{Tables}

Table 1 Comparison of amblyopia and lateral eye data in the experimental group

\begin{tabular}{|l|l|l|r|}
\hline Variable & \multicolumn{1}{|c|}{$\begin{array}{l}\text { Amblyopia eyes in the experimental } \\
\text { group } \\
(\mathrm{n}=17)\end{array}$} & $\begin{array}{l}\text { Lateral eyes in the experimental } \\
\text { group } \\
(\mathrm{n}=17)\end{array}$ & P \\
\hline BCVA & $0.24 \pm 0.22$ & 1.0 (median) & $<0.001$ \\
\hline SE $(\mathrm{D})$ & $4.35 \pm 2.98$ & $2.64 \pm 2.29$ & 0.043 \\
\hline $\begin{array}{l}\text { Macular fovea retinal thickness } \\
(\mu \mathrm{m})\end{array}$ & $207.82 \pm 17.79$ & $207.06 \pm 18.63$ & 0.883 \\
\hline Macular fovea VLD $\left(\mathrm{mm}^{-1}\right)$ & $7.31 \pm 3.84$ & $7.29 \pm 2.50$ & 0.985 \\
\hline Macular fovea PD & $0.16 \pm 0.08$ & $0.17 \pm 0.07$ & 0.701 \\
\hline FAZ area $\left(\mathrm{mm}{ }^{2}\right)$ & $0.28 \pm 0.17$ & $0.31 \pm 0.13$ & 0.510 \\
\hline FAZ perimeter $(\mathrm{mm})$ & $2.05 \pm 0.56$ & $2.26 \pm 0.54$ & 0.252 \\
\hline FAZ circularity & $0.67 \pm 0.06$ & $0.69 \pm 0.10$ & 0.592 \\
\hline
\end{tabular}

Table 2 Comparison of data between the experimental group and the control group

\begin{tabular}{|l|l|l|l|}
\hline Variable & $\begin{array}{l}\text { Amblyopia eyes in the experimental group } \\
(\mathrm{n}=17)\end{array}$ & $\begin{array}{l}\text { The control group } \\
(\mathrm{n}=17)\end{array}$ \\
& & P \\
\hline Age (years) & $13.88 \pm 9.73$ & $16.29 \pm 12.92$ & 0.543 \\
\hline Sex (male) & $8(47 \%)$ & $7(41 \%)$ & 0.730 \\
\hline BCVA & $0.24 \pm 0.22$ & $1.0(\mathrm{median})$ & $<0.001$ \\
\hline SE (D) & $4.35 \pm 2.98$ & $2.06 \pm 1.49$ & 0.009 \\
\hline Stereopsis (") & $800($ median) & $108.24 \pm 33.21$ & 0.150 \\
\hline Macular fovea retinal thickness $(\mu \mathrm{m})$ & $207.82 \pm 17.79$ & $209.47 \pm 13.89$ & 0.765 \\
\hline Macular fovea VLD $\left(\mathrm{mm}^{-1}\right)$ & $7.31 \pm 3.84$ & $7.89 \pm 3.87$ & 0.666 \\
\hline Macular fovea PD & $0.16 \pm 0.08$ & $0.17 \pm 0.10$ & 0.537 \\
\hline FAZ area (mm $\left.{ }^{2}\right)$ & $0.28 \pm 0.17$ & $0.31 \pm 0.13$ & 0.589 \\
\hline FAZ perimeter $(\mathrm{mm})$ & $2.05 \pm 0.56$ & $2.17 \pm 0.45$ & 0.508 \\
\hline FAZ circularity & $0.67 \pm 0.06$ & $0.69 \pm 0.10$ & 0.520 \\
\hline
\end{tabular}

\section{Figures}




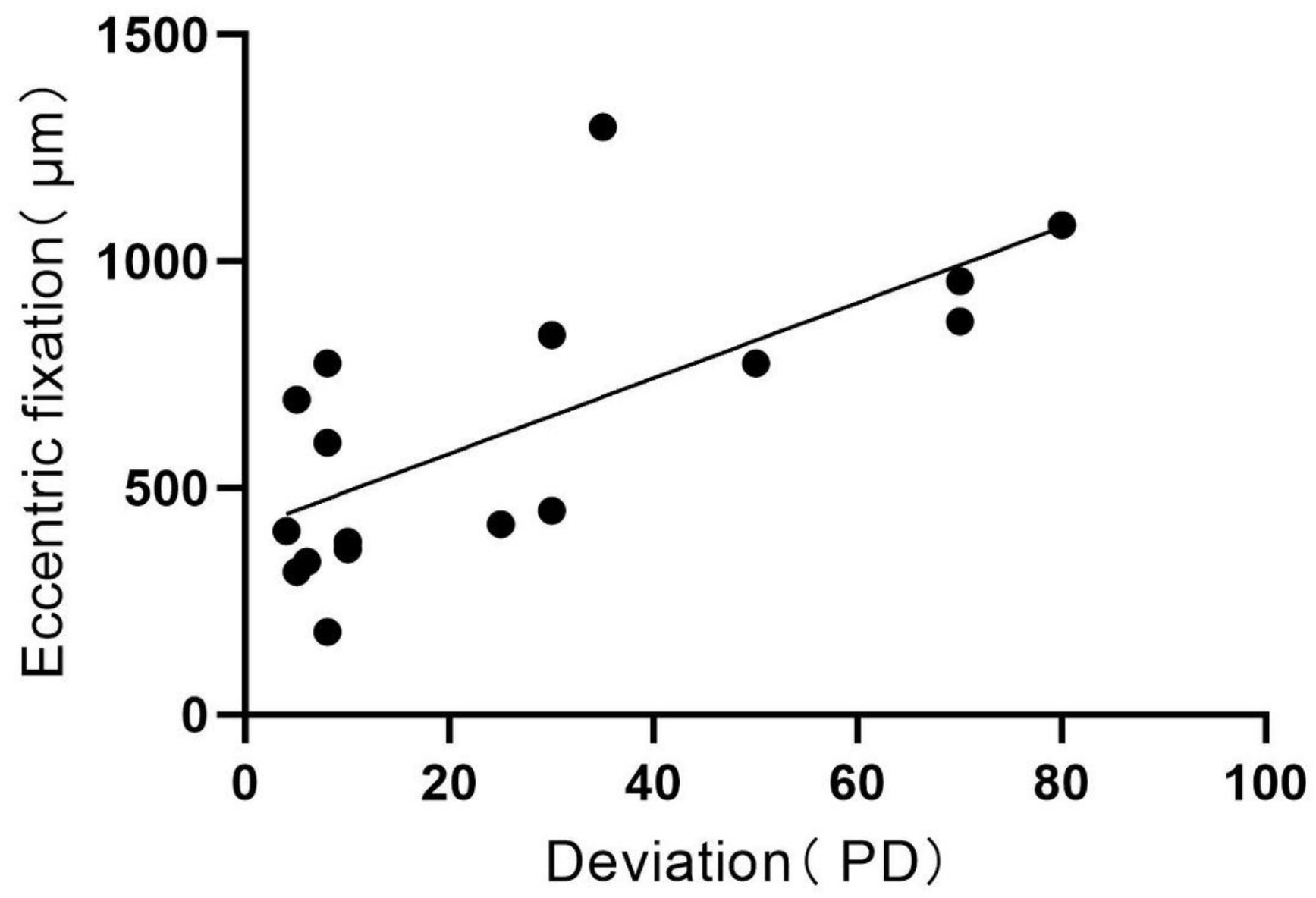

Figure 1

Relationship between the eccentric fixation distance and deviation 


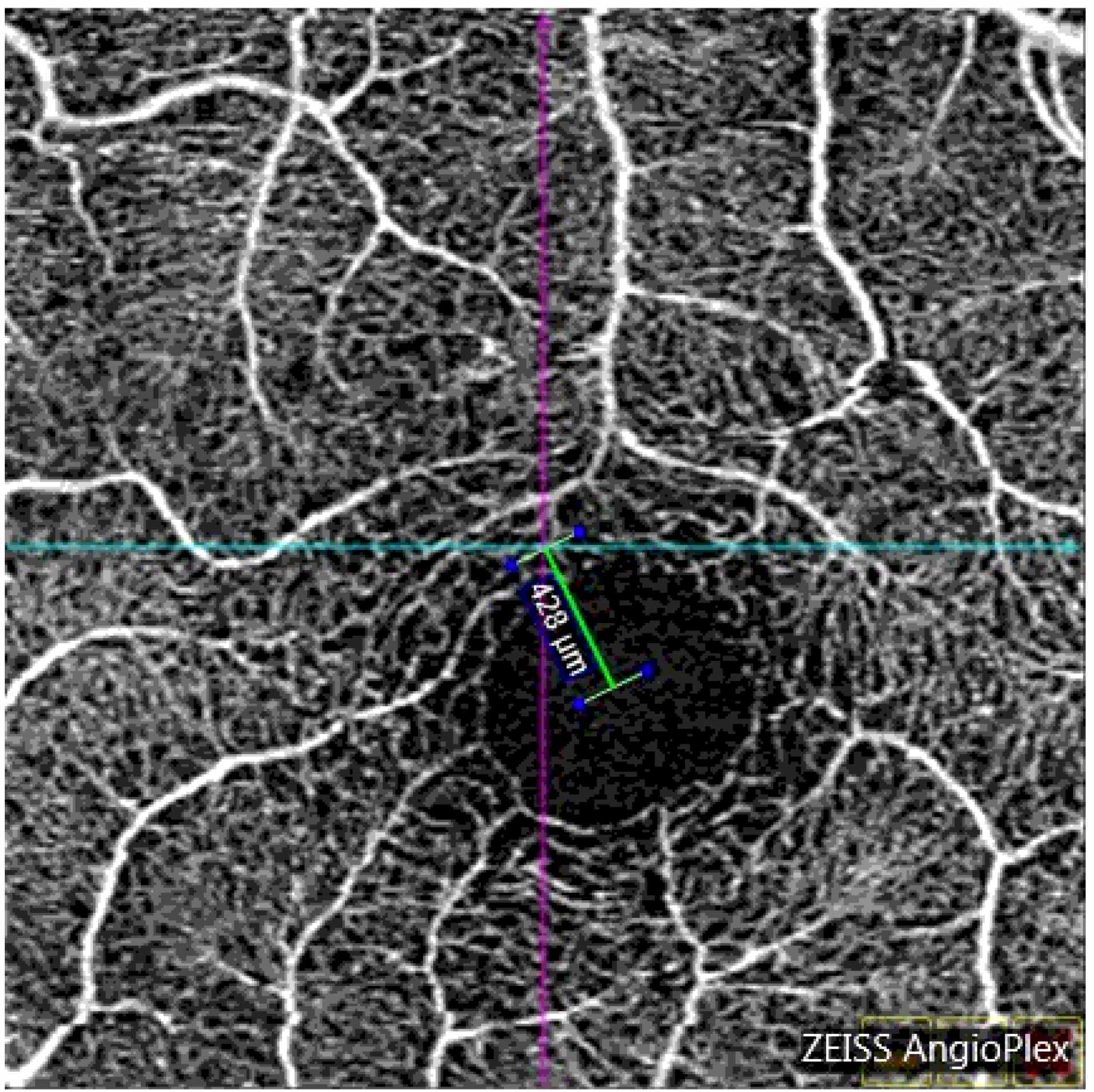

Figure 2

The navigation line is located in the centre of the image as the fixation point, measuring the distance between the fixation point and the centre of the macular fovea 


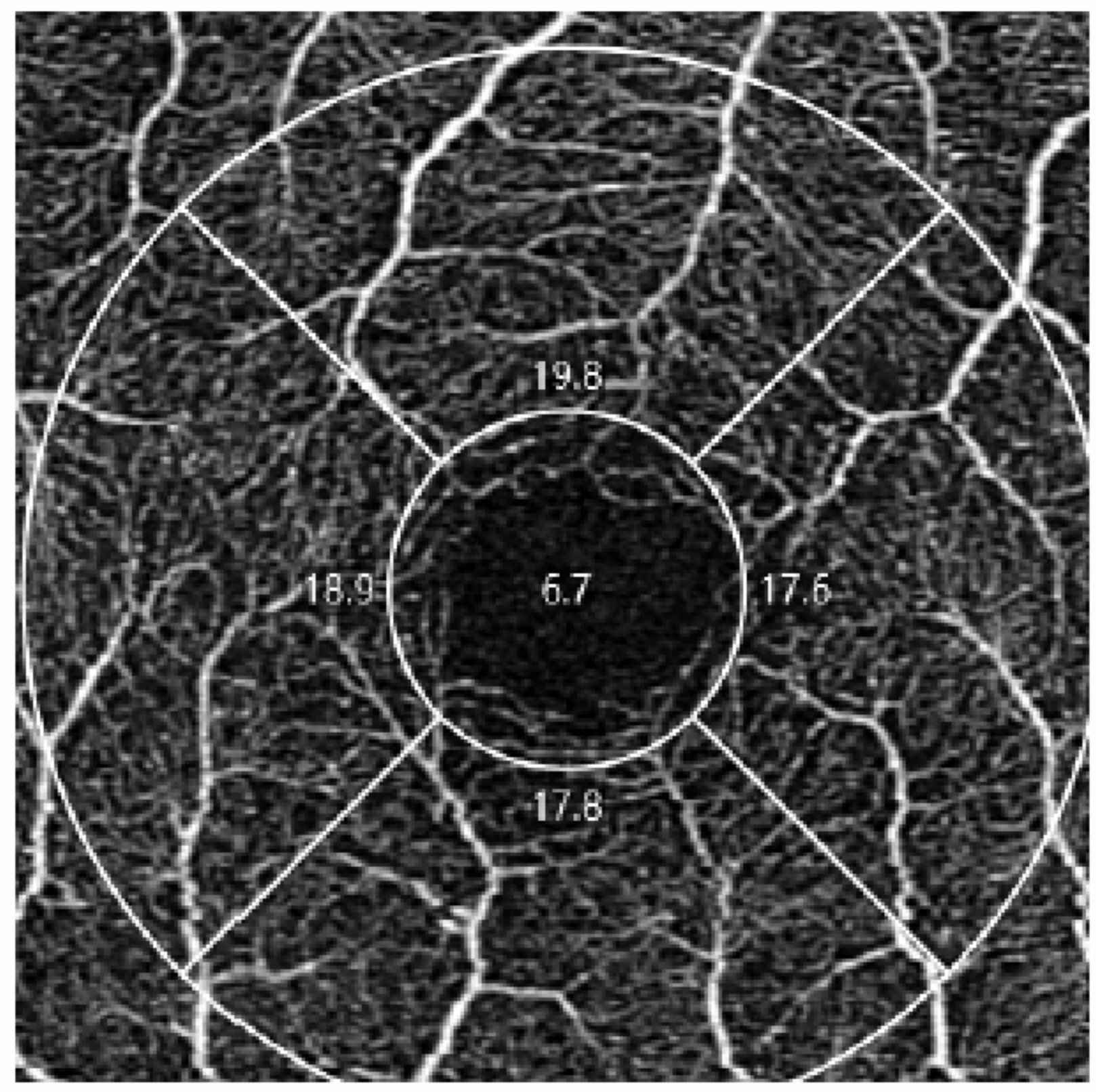

\section{Figure 3}

Automatic blood flow analysis of the superficial retinal vascular plexus macular fovea data using Angioplex software 